\title{
A PRELIMINARY ASSESSMENT OF RADICAL SURGERY IN CLEFT PALATE DEFORMITIES
}

\author{
DAVIES, DAVID, F.R.C.S.* \\ WHITING, D.M., B.A. LOG. (RAND), L.C.S.T. \\ MILLER, B.H., B.D.S. (RAND), D. ORTH. F.D.S. R.C.S. (ENG.) \\ CREMIN, B.J., M.B.B.S., M.R.C.S., M.C.R.A., F.F.R. \\ MORRISON, G., F.C.S. (S.A.) \\ *Plastic Surgery, Groote Schuur Hospital, University of Cape Town
}

\section{SUMMARY}

The development and aims of the Single Stage repair of complete clefts of the lip and palate are presented together with a preliminary account of results.

\section{OPSOMMING}

Die ontwikkeling en die doelstellings van 'n enkele stadium herstel van gesplete lip en verhemelte word aangebied saam met voorafgaande bepalinge van die resultate.

In the repair of cleft lip and palate deformities surgeons have always considered these two entities as separate deformities when corrective surgery was undertaken. Indeed many authorities $5,6,11,12,13$ today, still prefer to repair the lip alone at any age from 48 hours after birth to 3 months; followed later by correction of the hard palate deformity, and at the age of one year to eighteen months, a final operation to close the soft palate defect. Some indeed even regret the fact that the two deformities are associated. Consider this quotation from Brown and McDowell $\mathbf{1}$;

It is unfortunate that cleft lips so frequently coexist with cleft palate causing many surgeons to be preoccupied with closing part of the palate at the same time the lip is closed. Aside from the probability that early surgical treatment to the palate may result in unnecessary dental damage, it seems to us that good repair of the lip is difficult enough to require the surgeons undivided at tention in the process.

Perusing the literature we can see that there are those who follow the conventional pattern described above of lip repair - hard palate repair - soft palate repair. Veau ${ }^{14}$, who did much to stimulate modern cleft palate surgery, repaired lip and hard palate together, followed later by repair of the soft palate. Many followed this technique and Schmid ${ }^{8}$, Nordin and Johanson ${ }^{7}$, Schrudde and Stellmach ${ }^{9}$, combined this with an immediate autogenous bone graft to close the alveolor gap. Others such as Slaughter ${ }^{11}$, Schewendiek ${ }^{10}$ and Longacre ${ }^{3}$, feel that the lip should be closed early, and at six months the soft palate should be repaired leaving the hard palate unrepaired until the age 
of 6-8 years. In this interval an obturator is used to fill the defect in the hard palate. The rationale is that early clostire of the soft palate aids early and normal speech function while the untouched hard palate allows normal development of the maxillary arches, thus leading to less bony deformity and orthodontic disability.

At the Red Cross War Memorial Children's Hospital in Cape Town, our predecessors Dr. Norman Peterson and Dr. D.S. Davies, followed the early pattern of lip - hard palate - soft palate closure, and later changed it to lip and hard palate - soft palate closure. In 1964, we felt that a unilateral cleft lip and palate deformity should be treated as one congenital deformity and repaired at one operation. Our rationale for this was firstly technical; all the structures are easily accessible and the operation is in many ways easier than the multistage procedures. Secondly, the operation was completed in one stage which held many advantages for mother and child, especially as a large number of our patients came from far flung country districts, and under poor socio-economic conditions it is always easier for the mother to care for these infants if the palate has been reconstructed at an early age. Thirdly, we felt that the orthodontic aspect of this congenital deformity had been stressed at the expense of speech. Normal speech, after all, should be the prime objective of all surgeons working in this field, and if this more extensive operation held forth the promise of improved speech results because of early complete closure, then it should be completely investigated.

\section{Surgical Procedures}

A series of operations was started ${ }^{2}$ and an effort was made to standardise the operation so that in our assessment of the speech and orthodontic results there should be as few variables as possible. We plan to complete 50 cases with a Z-Plasty lip repair, autogenous rib bone graft to alveolar gap, one layer vomerine mucosa repair of hard palate defect and a push back of the soft palate with a Millard ${ }^{4}$ island flap. The next 50 cases will have Z-Plasty repair of the lip, NO bone graft to alveolar gap, vomerine mucosa repair of the hard palate, and a 2 flap Wardill ${ }^{16}$ push back repair of the soft palate with $N o$ Millard island flap. Finally 50 cases with Z-Plasty repair of lip and simple modern Von Langebeck ${ }^{15}$ repair of palate with no push back of the soft palate. No patients will be excluded from this series because of the size of the congenital defect, and there will be no particular selection of cases to any of the above series.

With this series we should be able to show whether early surgery of this magnitude is dangerous for the child or not; whether primary bone graft inhibits maxillary growth; whether early closure of the palate predisposes to more normal speech; whether early radical surgery leads to poorer orthodontic results and finally whether an island flap repair or a push back procedure has any advantages over a simple palatal closure. 
We have so far completed 95 cases and it seems possible at this stage to say that the procedure is not.technically difficult and there does not appear to be any added risk for the child. Blood loss over the series has averaged $10 \%$ of the blood volume, and the last twenty cases have lost only from 15 to 50 c.c. of blood, for a 2 hour procedure. Obviously these operations must be done by a cohesive team and under the best anaesthetic conditions.

It is clear from the above that we believe in early closure to achieve normal muscular action, at as early an age as possible. This principle should extend to simple clefts of the secondary palate, and bilateral complete clefts as well. Ten of these have been closed as a one stage procedure. Complete unilateral repairs have been done at 10 days of age, but in view of possible associated cardiac anomalies, which often manifest themselves only in the first month of life, we have now fixed our optimum age at 3 months. By this time the child should weigh nore than $4,5 \mathrm{Kgs}$. and have a normal haemoglobin level.

Obviously it is too early to draw any but the most sketchy and preliminary conclusions from this series. There is no place in any competent team for the Plastic Surgeon who attempts to assess his own results; these must be reviewed by a Speech Therapist and an Orthodontist.

\section{Speech Assessment}

The format of the Speech Assessment used in our clinics is specifically designed for its clinical implications for future management of each individual case.

Velopharyngeal competence is judged objectively on tests and subjectively in spontaneous speech on a 4 point scale. Mixed or deficient nasal resonance is noted when present.

Articulation is assessed in words first with the nose open and then all errors are checked with nostrils closed to determine whether the error is due to inadequate intra oral air pressure or incorrect placement of articulators. Errors in tongue-tip consonants are checked with particular reference to irregularities in the anterior maxillary arch and upper dentition. A particular note is made as to whether articulation deteriorates in spontaneous speech or not.

A - RESONANCE

A1 Normal Resonance.

A2 Slightly Excessive Nasal Resonance.

A3 Medium Nasal Resonance.

A4 Gross Nasal Resonance. 
B - ARTICULATION

B1 No articulation errors.

B2 One or two articularion errors only.

(NB Phonetic equivalents such as $s, z, ; t, d ; k, g$; i.e. voiced and voiceless counterparts are counted as 1 error.)

B3 Three or more articulation errors, but intelligible.

(NB A patient with only 2 articulation errors in words, but whose articulation deteriorates in spontaneous speech is classified as B3.)

B4 Multiple articulation errors - unintelligible.

Examples of:

B2 1. $s, z ; r$ (2 errors)

2. $s, z ; ; t, d$ (2 errors)

3. $s, z, ; s h, g e(2$ errors)

B3 1. $\mathrm{s}, \mathrm{z}, ; \mathrm{sh}, \mathrm{ge} ; \mathrm{ch}, \mathrm{j}$. (3 errors)

2. $\mathrm{s}, \mathrm{z}, ; \mathrm{t}, \mathrm{d},, ; \mathrm{r}$ (3 errors)

3. $s, z, ; s h ; c h ; r$ (4 errors)

B4 Plosives as glottals, distortions or omissions of sibilants.

\section{CLASSIFICATION EXAMPLES}

A1 B1 Normal Speech.

A1 B3 Normal resonance, 3 or more articulation errors.

A2 B2 Slight nasal resonance, 1 or 2 articulation errors.

A3 B1 Medium nasal resonance, no articulation errors.

A4 B4 Gross nasal resonance. Multiple articulation errors; unintelligible.

To be classified as B2, a child's articulation errors remain the same in spontaneous speech as in words. The child who has only one or two articulation errors in words but whose articulation deteriorates in spontaneous speech is classified as B3.

The results of the speech assessment together with results of X-Ray, Hearing evaluation, and case history will indicate whether the residual speech defect is due to:-

a) Anatomical anomalies of

1) Velopharyngeal mechanism

or 2) Anterior maxillary arch and dentition.

b) Incompetence of function

c) Other factors such as hearing loss, developmental lag, mental retardation, or cultural deprivation, etc.

We include some preliminary figures from the one stage repair series, but it must be emphasised that this is an incomplete series, and we feel that some of these cases can be expected to improve as they grow up. 
Unilateral Cleft Lip and Palate - One Stage Repair Series

\begin{tabular}{|c|c|c|c|c|c|c|}
\hline$A 1$ & $A 2$ & $A 3$ & $A 4$ & $\begin{array}{l}\text { Complete } \\
\text { Assessment }\end{array}$ & $\begin{array}{c}\text { Incomplete } \\
\text { Assessment }\end{array}$ & Total \\
\hline 11 & 11 & 4 & 1 & 27 & 19 & 46 \\
\cline { 4 - 7 } & $B 2$ & $B 3$ & $B 4$ & $\begin{array}{c}\text { Complete } \\
\text { Assessment }\end{array}$ & $\begin{array}{c}\text { Incomplete } \\
\text { Assessment }\end{array}$ & Total \\
\hline$B 1$ & 9 & 9 & 3 & 27 & 19 & 46 \\
\hline 6
\end{tabular}

Table I Analysis of speech Results

Assessments between 1.1 .70 and $30.4 .72-20$ cases Age range - 4 yrs. -9 yrs.

Assessment between 1.1 .68 and $31.12 .70^{\circ}-7$ cases Age range -4 yrs. -10 yrs.

Incomplete assessments - 19 cases in May' 72

\begin{tabular}{|c|c|c|c|c|}
\hline$A 1$ & $A 2$ & $A 3$ & $A 4$ & Total \\
\cline { 2 - 5 } 9 & 6 & 4 & 1 & 20 \\
\cline { 2 - 5 } & $B 2$ & $B 3$ & $B 4$ & Total \\
\hline 5 & 7 & 6 & 2 & 20 \\
\hline
\end{tabular}

Table II Analysis of Complete Assessments at follow-up between 1.1.71 - 30.4.72

\section{Orthodontic Assessment}

No pre-surgical dental orthopaedics has been carried out on the maxillary arches of these patients.

Orthodontic assessment is made on:-

1. MODELS

Pre-operative Intra Oral impressions of both upper and lower jaws are taken in the operation theatre immediately before the operation with the child anaesthetised. They are cast in stone and trimmed so that the correct relationship is shown between the upper and lower dental arches.

These models are repeated usually at yearly intervals or at the appropriate time to show dimensional changes. 


\begin{tabular}{|c|c|c|c|c|c|c|}
\hline & $A 1$ & $\dot{A 2}$ & $A 3$ & $A 4$ & Total & Group Total \\
\hline $\begin{array}{l}\text { + Island } \\
\text { Flap }\end{array}$ & 4 & 7 & 2 & 1 & 14 & \multirow{2}{*}{$\begin{array}{l}27 \\
.\end{array}$} \\
\hline \multirow[t]{2}{*}{$\begin{array}{l}\text { - Island } \\
\text { Flap }\end{array}$} & 7 & 4 & 2 & & 13 & \\
\hline & $B 1$ & $B 2$ & $B 3$ & $B 4$ & Total & Group Total \\
\hline $\begin{array}{l}\text { + Island } \\
\text { Flap }\end{array}$ & 3 & 3 & 6 & 2 & 14 & \multirow{2}{*}{27} \\
\hline $\begin{array}{l}\text { - Island } \\
\text { Flap }\end{array}$ & 3 & 6 & 3 & 1 & 13 & \\
\hline
\end{tabular}

Table III Speech Results in relation to Island Flap in the 27 cases fully assessed.

\begin{tabular}{|c|c|c|c|c|c|}
\hline Age & $B 1$ & $B 2$ & $B 3$ & $B 4$ & Total \\
\hline 4 & 2 & 1 & 3 & 2 & 8 \\
\hline 5 & 3 & 4 & 2 & & 9 \\
\hline 6 & & 1 & 1 & & 2 \\
\hline 7 & 1 & 1 & & & 2 \\
\hline 8 & & 1 & & 1 & 2 \\
\hline 9 & & 1 & 2 & & 3 \\
\hline 10 & & & 1 & & 1 \\
\hline & & & 9 & 3 & 27 \\
\hline
\end{tabular}

Table IV Articulation and Age at Assessments of the 27 cases.

\section{CEPHALOMETRIC X-RAYS}

These are true lateral views of the skull and jaws taken with the head held in a fixed position, and at a standardised target film distance. They are therefore, strictly comparable to show growth changes in a longitudinal study.

A sample series of 30 cases was used for a preliminary survey. In this instance only the pre-operative and most recently taken dental models were used for assessment. The average age at operation was 6,7 months with a range from 4 months to two years. Final models of the dental arches were taken at an average age of 3 years, the oldest being 5 years and 10 months. 


\begin{tabular}{|c|c|c|c|c|c|}
\hline & $B 1$ & $B 2$ & $B 3$ & \multirow[t]{3}{*}{$B 4$} & Total \\
\hline $\begin{array}{l}\text { Maxillary Arch and } \\
\text { Dental Anomalies }\end{array}$ & 0 & 5 & 3 & & 8 \\
\hline Dysfunction & 0 & 2 & 1 & & 3 \\
\hline Other Factors & 0 & 2 & 3 & & 5 \\
\hline Undetermined & & & 2 & 3 & 5 \\
\hline $\begin{array}{l}\text { Normal } \\
\text { Articulation }\end{array}$ & 6 & & & & 6 \\
\hline Totals & 6 & 9 & 9 & 3 & 27 \\
\hline
\end{tabular}

Table $V$ Analysis of Causes of Articulation Errors.

Results show that $47 \%$ of these patients have a Class III relationship of the incisor teeth, i.e. the lower incisors occluding in front of the upper. The remaining $53 \%$ have a Class I. (or normal) occlusion. The maxillary minor segment showed varying degrees of collapse in $66,7 \%$ of cases. This was assessed by relating the teeth on the minor segment to the opposing mandibular teeth and noting the amount of collapse towards the midline.

Although the percentage of cases showing Class III incisor relationship and collapse of the minor segment may appear to be high, these figures compare quite favourably with those of other published series. Also in many of these cases, simple orthodontic treatment is all that will be required to bring about correction.

It will however, be necessary to follow up a larger number of cases over a longer period of time before any final conclusion can be reached regarding growth of the dento-facial complex.

\section{Radiological Assessment}

The radiological assessment of these cases consists of static and dynamic studies which are pre and post-operative. The static studies are cephalometric measurements which are performed in the first few months of life, using an infant cephalostat and sedation:

The dynamic studies are a joint examination done by a team which consists of at least the surgeon, radiologist, and speech therapist. The parents are also. often invited to attend. Children from 3 years upwards are examined by a pulsed image intensifier using a 5 inch (magnification $\times 1 \frac{1}{2}$ ) field projected" onto a television screen. The length and mobility of the soft palate, and its capacity for sustained naso-pharyngeal closure, during repeated set sentences, are noted and assessed. A simultaneous speech videotape recording is also 
made and interesting or difficult cases are immediately played back and restudied. The videotape can later be transferred by Kinescope camera onto $16 \mathrm{~mm}$. film for further study on an analector camera. The advantages of this method over $35 \mathrm{~mm}$. cine radiography are that it enables the team to make a definite and immediate assessment, as development and projection facilities are not required (except for the delayed studies). The irradiation exposure to the child, which can be considerable with cine radiography, is also greatly reduced.

The soft tissues of the pharynx are so well visualised in these lateral studies that no contrast material is required. A $70 \mathrm{~mm}$. camera study is also routinely performed (this involves no extra irradiation as it directly photographs the output phosphor of the image intensifier). These films are taken at 3 per sec. for 1,5 secs, using the sounds of Mmh; Aah; Eeh and Ssh to record palatal mobility and velopharyngeal closure.

The films are then mounted as four strips in a plastic envelope that is conveniently kept with the patient's hospital record folder, so that comparative studies are always available.

We feel that thorough long term assessment of these children will, in time, produce interesting figures of an unusual operative approach to the problem of cleft palate deformities.

\section{ACKNOWLEDGEMENT}

We would like to thank the Medical Superintendent of the Red Cross War Memorial Children's Hospital for permission to publish these figures and record our gratitude to Professor Louw and Professor Cywes for their continuing encouragement. Finally, we must acknowledge our debt to the Murray Trust Fund without whose generous gifts we would not have been able to undertake this research.

\section{REFERENCES}

1. Brown, J.B. and McDowell, F. (1945) Surgical repair of single cleft lips. Surg. Gynae. Obstet. 80,12.

2. Davies, D. (1970) The radical repair of cleft palate deformities Cleft Palate J. 7,550.

3. Longacre, J.J. (1970) Cleft Palate Deformation: Charles C. Thomas. Springfield, Illinois.

4. Millard, D.R. (1962) Wide and/or short cleft palate. Plast. Reconstr. Surg. 29,40.

5. Millard, D.R. (1971) in Cleft Lip and Palate. Grabb, C.W., Rosentein, S.W. and Bzoch, K.R. (Eds.), Little, Brown, Boston.

6. Musgrave, R.H. (1964) The Unilateral Cleft Lip, in Reconstructive Plastic Surgery, Converse, J.M. (Ed.), Saunders, Philadelphia. 
7.. Nordin, K.E. and Johanson, B. (1955) Fortschur, Kiefer Gesichts Chir., 1,168.

8. Schmid, E. (1955) Fortschur, Kiefer Gesichts - Chir., 1,37.

9. Schrudde, J. and Stellmach, R. (1959) Fortschur, Kiefer Gesichts Chir., 5,247.

10. Schweckendiek, H. (1966). Primary Veloplasty, in Treatment of Patients with Clefts of Lip, Alveolus and Palate, Schuchardt, K. (Ed.), Georg Thieme Verlag, Hamburg.

11. Slaughter, W.B. and Pruzansky, S. (1954). The rationale for velar closure as a primary procedure in the repair of cleft palate defects. Plast. Reconstr. Surg., 13,341.

12. Tennison, C.W. (1971), in Cleft Lip and Palate. Grabb, C.W., Rosenstein, S.W. and Bzoch, K.R., Little, Brown, Boston.

13. Trusler, H.M., Bauer, T.B. and Tondra, J.M. (1955). The Cleft Lip Problem. Plast. Reconstr. Surg. 16,174.

14. Veau, V. (1938). Bec-de Lievre, Masson et cie, Paris.

15. Von Langenbeck's surgical procedure. (1951) In Cleft Lip and Palate, Holdsworth, W.G., Heinemann Medical Books.

16. Wardill's surgical procedure (1951) In Cleft Lip and Palate, Holdsworth, W.G., Heinemann Medical Books. 